\section{SCIENCE IN SOUTH-WEST CHINA}

\section{THE PHYSICO-CHEMICAL SCIENCES}

BY DR. JOSEPH NEEDHAM, F.R.S.

British Council Cultural Scientific Mission in China

$\mathrm{O}$ WING to the course of the War and world conditions, Free China has now been isolated from the rest of the world for such a long time that an account of what our Chinese scientific colleagues have been doing will surely be of interest to readers of NATURE both in Britain and the United States. During the past few weeks, since my arrival, I have had excellent opportunities of seeing the work of Chinese men of science in all branches of their work, and the present opportunity of presenting a short account of it to the scientific workers of the other United Nations is an important one.

Kunming, the capital of Yunnan province, is an ancient Chinese city lying at the northern end of an extensive lake, in a large plain surrounded by mountains. The whole region, with its equable and sunny climate, both winter and summer, must be one of the most beautiful in the world, since the plain is not so large that the mountains are ever out of sight. An intensive agriculture is carried on, aided by an elaborate system of dykes and canals, their banks often raised high above the surrounding fields, and planted with pine-trees, conveying water from the mountain-sides, and dating from the Yuen Dynasty (about A.D. 1200). The scientific institutions are well scattered at different distances from the city, and transport is by horse-cart, charcoal-burning bus, 'jeep', lorry or car.

\section{The National Associated South-Western University}

The National Associated South-Western University (Hsi-nan Lien-ho Ta-Shioh), formed by a coalescence of Peiping, Chinghua and Nankai Universities, and perhaps the greatest teaching centre in Free China, has a campus not far from the city. President Mei Yi-Chi (the physicist) attends to internal and local affairs and President Chiang Mon-Lin (educationist) attends to outside affairs. Both are outstanding personalities, embodying the ideal of the Chinese scholar. All the departments are housed in 'hutments' built of mud brick, and roofed very simply with tiles or tin sheets, though some have curving roofs in the great tradition of Chinese architecture. Inside, the floors are beaten earth, with a little cement, and extreme ingenuity has been used in fitting up laboratories for research and teaching under these conditions. For example, since no gas is available, all the heating has to be done with electricity, and hence when the supply of element wire for heaters (home-made out of clay) ran out some time ago, work was at a standstill until it was found that gun lathe shavings from one of the Yunnan arsenals would do very well. When hæmatoxylin became unobtainable, it was found that a dye something very like it could be obtained from an orangecoloured wood native to Yunnan, Casalpinia sappan. When microscope slides could not be had, windowpanes broken by air raids were cut up, and the unobtainable cover-slips were replaced by local mica. For glass-blowing, the blowpipes are fed with the vapour of power alcohol (derived from molasses) passed through electric furnaces. Instances could be multiplied at length.

The campus of the University lies in scenery some- what resembling Upper Deeside, with its pine-trees and hills in the distance. There are no air-raid shelters, and the population scatters to the hills if a raid looks like being serious. Built into the floors of each mud-brick building are large petrol drums, and all the most valuable apparatus is lowered into these when the siren goes, in order to preserve it against anything but a direct hit. Even in its humble buildings, the Associated University has been bombed several times and many of the rows of huts destroyed.

In the Physics Department of the University (visited with Dr. Wu Yo-Hsün, dean of the Faculty of Science) the main research going on is on the distribution and other properties of cosmic rays, by Drs. Chao Chung-Yao and Ch'ang Wên-Yü (both from the Cavendish Laboratory, Cambridge). But as might be expected under present difficult conditions, more theoretical work is proceeding, and $\mathrm{Dr}$. Wu Ta-Yo recently published an important book on the vibrational spectra of molecules, which was printed just before the fall of Shanghai, and a copy of which has been sent to the Cavendish Laboratory. Radio physies problems are being studied by $\mathrm{Ma}$ Se-Chun and $\mathrm{Ma} \mathrm{Ta}-\mathrm{Yo}_{\mathrm{o}}$, and mathematical physics, thermodynamics, etc., by Wang Ch'u-Hsi (a pupil of Sir Ralph Fowler) and Huang Tzu-Ching. Prof. Yao Yu-Tai (dean of the Faculty of Science at Peiping University) and Prof. Hsiung Ching-Lai had as their pupil the eminent young mathematician, Hua LoKung, a collaborator of Prof. G. H. Hardy.

The chemical side is mainly directed by Profs. Yang Shih-Hsien and Tsêng Chao-Lun, both organic chemists. One of the principal problems is the investigation of the alkaloids and glucosides in the anti-malarial drugs of the classical Chinese pharmacopoia; this is of much importance in relation to the existing world quinine shortage. There is also a group working with Dr. Ch'u Rju-Hua at the Peiping Institute; her interest lies in the migration aptitude of groups in phenanthrene pinacol compounds, and in the possible relation of vitamin $K$ to the sulphanilamide drugs. Prof. Tsêng and his collaborators are working on glycol lubricants. Unfortunately, as in all the other chemical laboratories I have seen here, the work is seriously hampered by lack of chemical reagents, and the supply of these seems almost more immediately necessary than the supply of books and periodicals. Chemical engineering is taught by Dr. Hsieh Ming-Shan (a pupil of Sir Alfred Egerton), and among the physical chemists is Chien Jen-Yuen (a pupil of Prof. C. N. Hinshelwood). It was a pleasure to see on the shelves of the working library a complete set of the Journal of the Chemical Society and other journals, presented by the University of Oxford.

Not all the research institutes of Peiping, Chinghua and Nankai-Universities were absorbed into the United University. Out at Dragon King Pool, about two hours distant from the city, are some of the Chinghua Institutes, notably that of mineralogy and metallurgy (Dr. Wang Tsun-Ming), that of radio physics (Dr. Rjên Chih-Kung), and that of crystal physics (Dr. Yu Shui-Huang, a former collaborator of the Braggs). The first of these co-operates with the Yunnan Geological Survey in assaying the numerous interesting and rich ores newly discovered in the province, and has found new alloys with important thermo-electric properties. The second is occupied with telecommunications, and has complete apparatus for making experimental valves in these rustic surroundings. The third possesses good equip. ment, all made in Yunnan, such as a Debye-Scherrer 
powder erystal camera, Laue oscillating camera, ete. The altitude of Kunming (some 6,000 ft. above sealevel) is so high that the spark-gap setting is affected. These institutes have good workshops, but they would have very much better ones if financial support were available to set up and mun some of the machines which were saved from the east or smuggled through the Japanese lines after the fall of Peiping and Hankow. There is also a great difficulty for all scientific institutions here, namely, that the university or Government wage for technical assistants is much smaller than what they can earn by going into business in a time of rise in prices which may truly be called gigantic. I shall have more to say on this subject in the following article.

\section{National Academies}

Besides the universities in China there are also two national academies: the Chinese National Academy (Chung Yang Yen Chiu Yuan) and the Peiping Academy (Peiping Yen Chiu Yuan). Of the ten research institutes of the former, three are located in the neighbourhood of Kunming, those of astronomy, chemistry and engineering. The astronomical observatory, exiled, alas, from its beautiful buildings on the Purple Mountain near Nanking, is situated a long way out in another direction from Kunming, at Big Tree Village. One of the members of the staff there is Dr. Tai Wên-Sai of Cambridge, formerly a collaborator of Prof. F. J. M. Stratton. The chemical institute is nearer town, and work is going on there on ultra-violet spectral analysis of organic and inorganic compounds, as well as on the active principles of local drugs, under the direction of Dr. Wu Shioh-Chou. The engineering institute is largely occupied with glass technology and metallurgical problems. Its workshop constructs all kinds of apparatus, such as kymographs and respirometers, for other scientific institutions.

The physics and chemistry sections of the Peiping Academy are located some three hours out, again in another direction, at a beautiful spot in the foothills near White Jade Hill. Here the physics section, under the direction of Dr. Ni Chi-Sse and Dr. Tsien Ling-Chao, has turned over almost wholly to war production, and a most remarkable plant for grinding lenses for microscopes, telescopes, etc., has been set up. The Academy is actually producing microscopes for teaching and research, having worked out all its own necessary apparatus, such as spherometers, etc. It is dependent on optical glass from England, however. Besides this, entirely new methods have been developed for making quartz pieze-electric crystals for frequency stabilization in radio work, and these are being produced in regular quantity, so that a supply may be available for the other United Nations. A point of interest here is that Dr. Tsien Ling-Chao has worked on the history of science in China, and has studied the optical chapters in the works of the classical Chinese philosopher, Mo-Tze (c. 400 B.c.). The Peiping Academy has also a section of chemistry, presided over by Dr. Liu Wei-Tao. Here also work is proceeding on the indigenous anti-malarial drugs by Dr. Wang Hsiu, an Austrian-trained organic chemist, and on the anthraquinone compounds of the rhubarb family.

\section{Central Machine Works}

Together with some of the members of the Peiping Academy, I paid a visit to one of the largest engineering works in China, the (State) Central Machine
Works, which is established in a mountain valley in Yunnan, and employs thousands of workers. Here it was a remarkable sight to see the elaborate apparatus for making fine tools, gear wheels, and other engineering parts requiring high accuracy, hidden away from the risk of air bombing in tunnels and artificial caves in the hillside. In the depth of the mountain one could see a Chinese skilled worker checking the accuracy of the machining on a Zeiss universal measuring machine in a constant-temperature room. Or one could view a scene resembling the cavern of Hephrstus, except that the ovens were of the most modern gas-filled kind used for tempering machined steel parts. Elsewhere are a vast foundry and assembling shops. There is an impressive system of apprenticeship, with special shops for training the young fitters and machinists. The main output of the factory is primary machinery such as drilling, planing, milling, boring and rolling machines, which are supplied to arsenals and other works, and the finished products, standing in their rows, were very impressive. These works really deserve an article to themselves. The whole is under the direction of an engineer (a former physicist), Dr. Wang Shou-Chin. Dr. Wang's father, Dr. Wang Chi-Tong, now a venerable figure of seventy, is also interesting. Himself the son of a Hanlin scholar, he was one of China's first modern engineers, and is now in his retirement devoting himself to the study of Buddhism in relation to modern thought.

Description of the Central Machine Works affords an opportunity for mentioning one very hopeful sign observable there, namely, the effort on the part of the Chinese to get away from the bad side of their old traditions of scholarly aloofness from manual labour, and the old system of excessive politeness. In these works, fully trained university graduates in engineering are working side by side with the ordinary workers, taking active day-to-day charge of each special process and controlling every stage. This is really a change from the old graduate's attitude to practical work. The same improvement may be seen in the atmosphere at the National Vaccine Production Institute (the National Epidemics Prevention Bureau), directed by Dr. T'ang Fei-Fên. Here once a week, as a kind of communal exercise, all the workers of the Institute, including the medical men, bacteriologists, etc., as well as the glass-makers, the routine fillers and samplers, the stables staff, etc., join together in levelling and improving the site so as to convert it into a healthy garden.

\section{Geology}

It only remains to describe a little of the work of the geologists. The geologists of the Associated University (led by Profs. Sun Yuing-Ch'u, a former collaborator of Prof. J. E. Marr at Cambridge, and Yuan Fu-Li) work in close association with the Yunnan Geological and Mineralogical Survey, and together they have investigated large parts of the province. A picturesque old house in the country has been appropriated to the purposes of a museum, and there a very fine collection has been assembled, with separate sections for stratigraphy, ores, palæontology, etc. Yunnan is an area extremely rich in mineral resources, having admirable ores of antimony, arsenic, zinc, copper, iron, cobalt, tungsten and tin, as well as coal, lignite, rocksalt, asbestos and mica. Phosphate deposits are widespread, with phosphorus content as high as 38 per cent. 